although these numbers are quite small. Perhaps of more importance, in only $26 \%$ of the patients with glaucoma referred by general practitioners was a screening test the reason for the referral.

These results show that ophthalmic practitioners and opticians detect most of the glaucoma in patients referred to the Oxford Eye Hospital. The reasons probably include increased suspicion and screening efforts, more effective use of screening tests, and patient choice in seeking care. Regarding the various screening tests, the observation of cupping on fundoscopy was by far the most common means of detecting glaucoma by general practitioners and opticians or ophthalmic practitioners.

Since the eye hospital is the major referral centre for the county of Oxfordshire, these results provide a reasonable basis for broader generalisation of the "who" and "how" of detecting glaucoma in the United Kingdom at present.

Opticians and ophthalmic practitioners should be aware of their role in detecting glaucoma. Perhaps screening for glaucoma should be part of their routine eye examination. General practitioners should realise that the ophthalmoscope may be the only tool needed to enable them to contribute to the detection of glaucoma, provided that they can recognise cupping on fundoscopic examination and foster some degree of suspicion for this disease. The potential role of the fundoscopic examination in screening for glaucoma deserves further evaluation, as does the possible part that general practitioners could play in detecting glaucoma.

J I Mann and M P Vessey at the Department of Community Medicine and General Practice, and Fred Ederer from the National Eye Institute, Bethesda, were extremely helpful in the design of this study. P N Awdry, A J Bron, H Cheng, and A Freedman, Oxford Eye Hospital, Oxford, kindly granted permission to study their clinic patients. The clerical staff at the Oxford Eye Hospital provided invaluabe help in collecting the data. A $\mathrm{K}$ Diehl from the University of Texas, San Antonio, and R S Wigton from the University of Nebraska, Omaha, provided editorial help.

This work was funded by the Milbank Memorial Fund, New York.

\section{References \\ 1 Standing Medical Advisory Committee for the Central Health Services Council and the Ministry of Health. The prevention and alleviation of blindness. London: HMSO, 1962. \\ 2 Briggs AH. Detection of glaucoma. Br Med F 1963;i:256-7. \\ 3 Anonymous. Detection of glaucoma. $\mathrm{Br} \mathrm{Med} \mathcal{F}$ 1963;i:624. \\ 4 Day PP. Detection of glaucoma. Br Med f 1962;ii:1257. \\ 5 Walker WM. Unsuspected chronic glaucoma. Br Med f 1963;ii:1590. \\ ${ }^{6}$ Graham PA. Screening for chronic glaucoma. Proc $R$ Soc Med 1966;59: 1215-20.}

(Accepted 14 April 1982)

\title{
Referral routes to hospital of patients with chronic open-angle glaucoma
}

\author{
J M MACKEAN, A R ELKINGTON
}

\begin{abstract}
An analysis of the referral routes to Southampton Eye Hospital of 191 patients who had been diagnosed as having chronic open-angle glaucoma showed that 121 patients $(63.4 \%)$ were diagnosed as a result of the patient seeking advice for ocular symptoms (118) or because they had a family history of glaucoma (3). Advice had been sought from general practitioners (48), ophthalmic medical practitioners (19), and ophthalmic opticians (46). The remaining eight patients had gone directly to the casualty department. Seventy patients had been identified by chance, the majority by ophthalmic medical practitioners (26) or ophthalmic opticians (32).
\end{abstract}

\section{Introduction}

In 1978 an estimated 10000 people in the United Kingdom were reported blind from the visual field loss due to chronic open-angle glaucoma. ${ }^{1}$ The estimated prevalence figures for the disease in the community vary and depend on the criteria used for diagnosis. ${ }^{2}$ Even the lowest estimate, however, is $0.4 \% .^{34}$

Chronic open-angle glaucoma is essentially a disease of the elderly. These patients often have to cope not only with the

\footnotetext{
University Surgical Unit, University of Southampton, Southampton SO9 5NH

J M MACKEAN, BA, DBo, research fellow

A R ELKINGTON, FRCS, DO, senior lecturer in ophthalmology
}

trials of presbyopia but also with the effects of lens opacities and degenerative changes at the macula. It is thus not surprising that they ascribe any but the most dramatic visual symptoms merely to their age. Against this background of widespread acceptance of failing vision, among this group is superimposed the fact that the earliest visual field loss of glaucoma occurs in the area adjacent to, but not affecting, the visual axis. The resulting islands of visual loss may not be noticed by the patient (especially if the vision of the fellow eye is good) or their effects may be put down simply to advancing years. Even if a defect is noticed the patients have an opportunity to adapt to the defect in their eyesight as the progression of the field loss is usually slow. It is not surprising, therefore, that many patients present late, though some may be fortunate and have the glaucoma suspected by an ophthalmic medical practitioner, a general practitioner, or an ophthalmic optician at a routine eye test.

The purpose of this study was to discover how many, out of a group of patients with chronic open-angle glaucoma, had noticed symptoms and by which route patients with this form of glaucoma were referred to hospital.

\section{Patients and methods}

So far as possible, all patients who lived in the Southampton and South-west Hampshire Health District and who had been diagnosed (between May 1977 and April 1980 inclusive) as having chronic openangle glaucoma were included in the study. The small number of private patients and those living, or had been referred after diagnosis from, outside the health district were excluded. Names were collected from the diagnostic index at Southampton Eye Hospital and from the outpatient clinic at Lymington Hospital.

Details of sex, date of birth, and referral routes were obtained from 
the hospital notes, and ocular morbidity (including the severity of the visual field loss) was noted. A severe visual field loss was defined as tunnel vision or a field loss affecting central vision or a remaining small central plus peripheral islands of vision. Patients were included in the study if, in addition to fulfilling the above criteria of place of residence and time of diagnosis, (a) they had an intraocular pressure of $21 \mathrm{~mm} \mathrm{Hg}$ or more, measured by Goldmann applanation tonometry, glaucomatous cupping of the optic disc, and a glaucomatous visual field loss in one or both eyes at the time of diagnosis and $(b)$ there was no evidence of angle closure.

Six sets of notes could not be traced. Two hundred and forty-nine patients fulfilled all the criteria. For each of these patients, the general practitioner was asked if he had any objection to his patient being interviewed. Replies indicated that eight patients had died, four had moved out of the district, and six were too ill or senile to be interviewed. Letters were then sent to the other 231 patients asking if they would be willing to take part in the study. It was found that a further six had died, three had moved out of the district, and 13 were not available for interview for health reasons. It was impossible to contact five patients and 13 preferred not to take part.

The remaining 191 patients were then interviewed in their homes, all by the same research worker (JM) using a structured questionnaire. The patient was asked who first noticed something wrong with their eyes and was then prompted to describe the referral route. Questions were asked about symptoms and how often they had had their eyes examined.

\section{Results}

The 191 patients in the study included 98 men, average age $69 \cdot 6$ years (range 39-88), and 93 women, average age 72.6 years (range 50-89). Eighty patients had an additional eye disease.

When the hospital notes were examined, it was found that 130 patients had been referred to Southampton Eye Hospital by their general practitioners, 38 by ophthalmic medical practitioners, five by ophthalmic opticians, and six by consultants from other departments. Eight patients had come directly to the casualty department and four were already attending the outpatient clinic for another eye condition (see below).

When the patients were interviewed, a more complete picture of the referral routes emerged. The patients were divided into two main groups-those who had been diagnosed as a result of a chance finding (70) and those who had sought advice because of ocular symptoms (118) or a family history of glaucoma (3). These groups were further subdivided as shown in table I. The two main groups will be considered separately.

TABLE I-Details of the two main referral groups

\begin{tabular}{|c|c|c|c|c|c|}
\hline & \multicolumn{2}{|c|}{ Chance finding } & \multicolumn{2}{|c|}{ Not chance finding } & \multirow{2}{*}{ Total } \\
\hline & Symptoms & $\begin{array}{c}\text { No } \\
\text { symptoms }\end{array}$ & Symptoms & $\begin{array}{c}\text { No } \\
\text { symptoms }\end{array}$ & \\
\hline \multirow{2}{*}{$\begin{array}{l}\text { Other ocular } \\
\text { disorder present } \\
\text { No other ocular } \\
\text { disorder present }\end{array}$} & 14 & 7 & 59 & 0 & 80 \\
\hline & 13 & 36 & 59 & 3 & 111 \\
\hline $\begin{array}{l}\text { Subtotal } \\
\text { Total }\end{array}$ & 27 & 43 & $118 \quad 12$ & 3 & 191 \\
\hline
\end{tabular}

\section{PATIENTS DIAGNOSED AS A RESULT OF A CHANCE FINDING}

Seventy patients were diagnosed as the result of a chance finding. Of these, 43 had noticed nothing wrong with their eyes before diagnosis, including one patient with a severe visual field loss in both eyes and two who were severely affected in one eye. Among the 27 patients (nine with a severe visual field loss in one eye) who had noticed a defect, 12 had attributed this to their age.

Four of the 70 patients mentioned above had their glaucoma diagnosed initially in the outpatient clinic. Three had been suffering from ocular hypertension (these are classified here as having no ocular disease apart from glaucoma) and the fourth from senile macular degeneration. Table II shows the people concerned in the initial referral of the other 66 patients and where they referred them.
TABLE II-People concerned in the chance finding of 66 patients. (Figures in parentheses refer to patients who had no other ocular pathology)

\begin{tabular}{|c|c|c|c|c|}
\hline \multirow[b]{2}{*}{ Source of initial referral } & \multicolumn{4}{|c|}{ No of patients referred } \\
\hline & $\begin{array}{l}\text { Direct } \\
\text { to eye } \\
\text { hospital }\end{array}$ & $\begin{array}{l}\text { Via GP } \\
\text { to eye } \\
\text { hospital }\end{array}$ & $\begin{array}{l}\text { Via OO } \\
\text { to eye } \\
\text { hospital }\end{array}$ & Total \\
\hline $\begin{array}{l}\text { General practitioner } \\
\text { Ophthalmic medical practitioner } \\
\text { Ophthalmic optician (OO) } \\
\text { Other department* } \\
\text { Routine medical }\end{array}$ & $\begin{aligned} & 1 \\
& 21(16) \\
& 1(1) \\
& 5(3) \\
&-\end{aligned}$ & $\begin{array}{l}5 \overline{(3)} \\
31(21) \\
1 \overline{1(1)}\end{array}$ & $\begin{array}{l}1(1) \\
= \\
-\end{array}$ & $\begin{aligned} 2 & (1) \dagger \\
26 & (19) \\
32 & (22)_{+}^{+} \\
5 & (3) \\
1 & (1)\end{aligned}$ \\
\hline Total & $28(20)$ & $37(25)$ & $1(1)$ & $66(46)$ \\
\hline
\end{tabular}

*Other departments were the diabetic clinic (4 patients) and the neurological department (1 patient).

tOne of the two patients had consulted his general practitioner for systemic hyper-
tension, the other was having a medical examination for insurance purposes.

$\ddagger$ Of the 58 patients initially referred by ophthalmic medical practitioners or ophthalmic opticians, 49 were having a routine refraction, seven had broken their
glasses, and two had been told to have a routine eye test for the firm for which they worked (Esso).

\section{PATIENTS WHO SOUGHT ADVICE}

One hundred and twenty-one patients initiated the referral by seeking advice. Of these, 12 patients had a severe field loss in both eyes at presentation and 35 in one eye. Table III shows the main reasons for the initial referral and the person whose advice had been sought. Eleven of the 23 patients who described a visual field loss when interviewed said that they had not mentioned this particular fact either to the person who had initially referred them or to the hospital doctor.

It was also discovered that out of the 65 patients who consulted either an ophthalmic medical practitioner or an ophthalmic optician, six had never had their eyes tested before, 30 had had glasses but did not go for regular checks, and the other 29 patients did go for twoyearly checks but were not due for one at the time of this visit.

The routes of referral of patients who sought advice from their general practitioners, an ophthalmic medical practitioner or an ophthalmic optician are illustrated in the flow chart (fig).

Table IV summarises the part played by the three professional groups concerned in the primary referral of patients to Southampton Eye Hospital.

TABLE III-Reasons for patients seeking advice and people whose advice was sought. (Figures in parentheses refer to patients with no other ocular pathology)

\begin{tabular}{|c|c|c|c|c|c|}
\hline \multirow{2}{*}{$\begin{array}{l}\text { Reasons for } \\
\text { consultation }\end{array}$} & \multicolumn{4}{|c|}{ To whom patients went for advice } & \multirow{2}{*}{ Total } \\
\hline & GP & OMP & $\mathrm{OO}$ & Casualty & \\
\hline Deterioration of vision & $22(9)$ & $15(9)$ & $30(12)$ & $4(2)$ & $71(32)$ \\
\hline Visual field loss & $10(8)$ & $1(1)$ & $11(10)$ & $1(1)$ & $23(20)$ \\
\hline Pain & $2(1)$ & $2(2)$ & 2 & $1(1)$ & $7(4)$ \\
\hline Floaters & 2 & - & $2(2)$ & - & $4(2)$ \\
\hline Haloes & $3(1)$ & - & - & - & $3(1)$ \\
\hline \multirow{2}{*}{$\begin{array}{l}\text { Other-for instance, } \\
\text { infection }\end{array}$} & 1 (1) & $1(1)$ & $1(1)$ & - & $3(3)$ \\
\hline & 8 & - & - & 2 & 10 \\
\hline $\begin{array}{l}\text { Subtotal } \\
\text { Total }\end{array}$ & $48(20)$ & $\begin{array}{r}19(13) \\
6\end{array}$ & $\begin{array}{l}46(25) \\
38)\end{array}$ & $8(4)$ & $121(62)$ \\
\hline
\end{tabular}

OMP $=$ Ophthalmic medical practitioner

$\mathrm{OO}=$ Ophthalmic optician

TABLE IV-Part played by the three professional groups in the primary referral of patients to Southampton Eye Hospital. (Figures in parentheses refer to patients with no other ocular pathology)

\begin{tabular}{lcccc}
\hline \multirow{2}{*}{ No of patients } & \multicolumn{3}{c}{ Professional group } & \multirow{2}{*}{ Total } \\
\cline { 2 - 4 } & GP & OMP & OO & \\
\hline $\begin{array}{c}\text { Consulted professional because } \\
\text { of ocular symptoms (110) or a } \\
\text { family history of glaucoma (3) }\end{array}$ & $52(23)$ & $19(13)$ & $42(22)$ & $113(58)$ \\
$\begin{array}{l}\text { Consulted professional for other } \\
\text { reasons (= chance finding) }\end{array}$ & $2(1)$ & $26(19)$ & $32(22)$ & $60(42)$ \\
\hline Total & $54(24)$ & $45(32)$ & $74(44)$ & $173(100)$ \\
\hline
\end{tabular}

Not included in this table are patients who had been referred from other sources (6), those who had gone directly to the casualty department (8), and those who were being followed up in the outpatient department for another condition (4). OMP $=$ Ophthalmic medical practitioner .

$\mathrm{OO}=$ Ophthalmic optician.

\section{象}




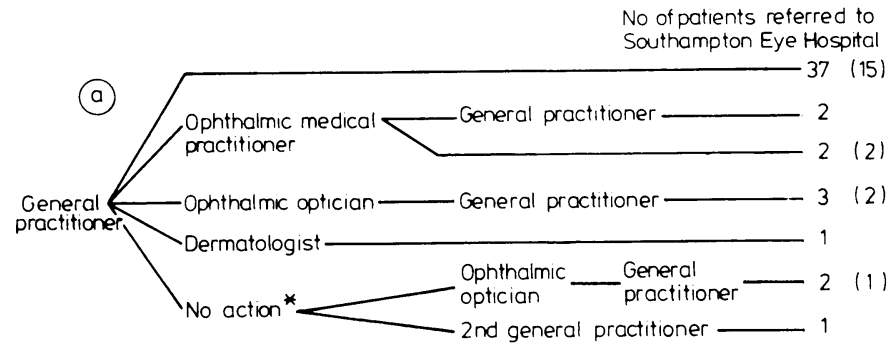

(b)

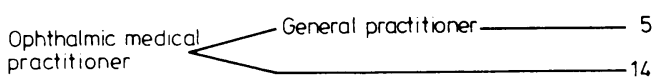
practitioner $(10)$

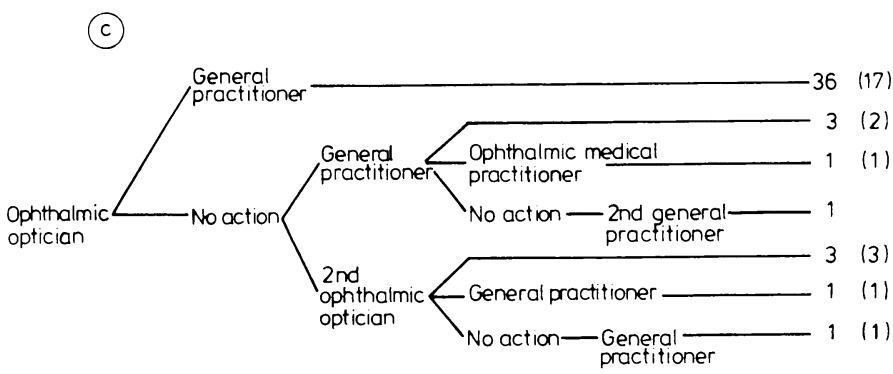

Referral routes of (a) 48 patients who consulted their general practitioner (b) 19 patients who consulted an ophthalmic medical practitioner, and (c) 46 patients who consulted an ophthalmic optician. Figures in parentheses refer to patients who had no other ocular disorder. "No action" indicates that the disease was not recognised and that the patient therefore needed a further consultation.

\section{Discussion}

It is well recognised that many patients with symptoms do not necessarily seek advice. A study among the general population in Scotland ${ }^{5}$ found that $88 \%$ of those interviewed had physical symptoms. Less than a third of those patients with symptoms had sought professional advice. It has been suggested ${ }^{6}$ that expectations in terms of health become lower with increasing age and that minor deviations from normal are tolerated. Of the 145 of our patients who had noticed symptoms, 118 had sought advice while 27 had not. Of these 27 , nine had a severe visual field loss in the worse eye by the time that the disease was diagnosed. Glaucoma characteristically affects elderly patients who may have other eye disorders. We found that of those who had symptoms half had additional disorders. Of the 111 patients with glaucoma alone, $49(44.1 \%)$ had had their disease diagnosed by chance.

General practitioners played an important part in referring patients who consulted them about either ocular symptoms or a positive family history. They played a lesser part, however, in the chance finding of patients with glaucoma compared with ophthalmic medical practitioners and ophthalmic opticians, who played an almost equally important part.

We thank Mr M J Absolon, Mr I H Chisholm, Mr J McGill, and $\mathrm{Mr}$ C B Walker for their permission to interview patients under their care and also the staff of the medical records departments of Southampton Eye Hospital and Lymington Hospital for their help.

\section{References}

${ }^{1}$ Graham PA. Prevalence of glaucoma. Trans Ophthalmol Soc UK 1978; 98:288-9.

${ }^{2}$ Kahn HA, Milton RC. Alternative definitions of open angle glaucoma. Arch Ophthalmol 1980;98:2172-7.

${ }^{3}$ Hollows FC, Graham PA. Intraocular pressure, glaucoma, and glaucoma suspects in a defined population. Br $\mathcal{F}$ Ophthalmol 1966;50:570-86.

4 Kahn HA, Milton RC. Revised Framingham eye study prevalence of glaucoma and diabetic retinopathy. Am f Epidemiol 1980;111:769-76.

${ }^{5}$ Hannay DR. Factors associated with formal symptom referral. Soc Sci Med 1979;13A:101-4.

${ }^{6}$ Morrell DC. Symptom interpretation in general practice. $\mathcal{F} R$ Coll Gen Pract 1972;22:297-309.

(Accepted 1 fuly 1982)
I have heard it said that some families are prone to disorders such as hernia, haemorrhoids, varicose veins, slipped discs, etc, which imply some have "tissue weakness." Is there any evidence for this statement?

This is what might fairly be called the million dollar question; $\$ 100000$ reward for each of the four individual disorders mentioned and $\$ 60000$ for the etcetera. Dr Guy Daynes, who has worked for many years in the Transkei in South Africa, tells me that the native inhabitants of that area have veins with strong muscular walls, so that taking blood from a vein feels like an arterial puncture. He also tells me that varicose veins and haemorrhoids are very rare in these people. The constitutionally category C3 type of patient, flabby, atonic, and overweight with pendulous abdomen, who never takes any exercise, overeats, and often oversmokes and overdrinks would seem to be more prone to all these disorders than healthier subjects, but otherwise there seems to be no close correlation between the four disorders mentioned. All four are so common that they often co-exist. In the Ehlers-Danlos syndrome (a heterogenous group of inherited disorders with eight currently recognised subtypes with hyperelastic fragile skins and hyperextensible joints) the patients are more prone to abdominal hernias, and varicose veins, probably related to the loss of normal venous elasticity, are common. Such patients bruise readily. Such patients are more prone to arthralgia and premature osteoarthritis, ${ }^{1}$ mitral valve prolapse, and certain ocular abnormalities (ectopia lentis, keratoconus, redundant upper eyelids, and epicanthic folds). It is inherited as an autosomal dominant or recessive condition depending on the type. Patients of type IV have a type III collagen deficiency in skin and blood vessels, type VI a lysyl hydroxylase deficiency, ${ }^{2}$ and type VII R procollagen peptidase deficiency, but the biochemical defect is unknown in the other types. Considerable research has been done on the biochemical tissue changes with age and degeneration and work has been focused on changes in collagen and proteoglycans of the intervertebral discs, but "tissue weakness" may have many biochemical causes, and the families mentioned may well have several inherited predisposing conditions affecting several systems.-F DUDLEY HART, consulting physician, London.

'Beighton P. Articular manifestations of the Ehlers-Danlos syndrome. Semin Arthritis Rheum $1971 ; 1: 246-61$. McKusick VA. Heritable disorders of connective tissue. St Louis: C V Mosby
Company, 1972.

What is the cause of "cold weather itch" and how can it be treated or prevented?

I take it that this term refers to the common symptom of itchiness in cold weather without any gross skin disease or internal cause. A slight dryness of the skin is often the only physical sign. The usual explanation is that the water content of the stratum corneum acts as a plasticiser, and if it falls with the lowered ambient humidity of cold weather or excessive central heating the stratum corneum becomes brittle and allows minor irritants such as soap to penetrate causing mild inflammation and itching. The already dry skin of the legs of old people is especially susceptible to this process. Treatment is based on preserving the water content by using emollients such as soft white paraffin or E45, applied regularly and especially after a bath. Overwashing with soap should be reduced, and a non-alkaline substitute for soap such as aqueous cream is often helpful. Rough winter clothing should not be worn next to the skin. Often the condition is surprisingly stubborn, and in these cases the occasional use of a weak topical steroid in a greasy base is justified.- -J A SAVIN, consultant dermatologist, Edinburgh. 